\title{
A parameter-uniform Schwarz method for a singularly perturbed reaction-diffusion problem with an interior layer
}

\author{
J.J.H. Miller ${ }^{\text {a }}$, E. O’Riordan ${ }^{\text {b }}$, G.I. Shishkin ${ }^{\text {c }}$, S. Wang ${ }^{\text {d,* }}$ \\ a Department of Mathematics, Trinity College, Dublin, Ireland \\ b School of Mathematical Sciences, Dublin City University, Dublin, Ireland \\ c Institute for Mathematics and Mechanics, Russian Academy of Sciences, Ekaterinburg, Russia \\ d Department of Mathematics and Statistics, The University of Western Australia, Perth, Australia
}

\begin{abstract}
In this paper we consider numerical methods for a singularly perturbed reaction-diffusion problem with a discontinuous source term. We show that such a problem arises naturally in the context of models of simple semiconductor devices. We construct a numerical method consisting of a standard finite difference operator and a non-standard piecewise-uniform mesh. The mesh is fitted to the boundary and interior layers that occur in the solution of the problem. We show by extensive computations that, for this problem, this method is parameteruniform in the maximum norm, in the sense that the numerical solutions converge in the maximum norm uniformly with respect to the singular perturbation parameter. ๑ 2000 IMACS. Published by Elsevier Science B.V. All rights reserved
\end{abstract}

Keywords: Reaction-diffusion equation; Semiconductor device equation; Singular perturbation; Interior layer

\section{The semiconductor device equations}

The stationary behaviour of semiconductor devices can be described by the nonlinear system of second-order elliptic equations of van Roosbroeck [6]. In one dimension, for example, a simple $p-n$ diode $\Omega=(0,1)$ with two Ohmic contacts, an anode at $x=0$ and a cathode at $x=1$, is governed by the equations

$$
\begin{aligned}
& \psi^{\prime \prime}-\eta \mathrm{e}^{\psi}+\rho \mathrm{e}^{-\psi}=-D, \\
& \left(\mathrm{e}^{\psi} \eta^{\prime}\right)^{\prime}-R(\psi, \eta, \rho)=0, \\
& \left(\mathrm{e}^{-\psi} \rho^{\prime}\right)^{\prime}-R(\psi, \eta, \rho)=0
\end{aligned}
$$

on $\Omega$ with appropriate boundary conditions at $x=0$ and $x=1$. Here $\psi$ is the electrostatic potential, $\eta$ and $\rho$ are the electron and hole concentrations in the Slotboom variables, $D$ denotes the doping function

\footnotetext{
* Corresponding author. 
and $R$ denotes the recombination/generation rate. The doping function $D$ has a large jump at a point in $\Omega$, called the $p-n$ junction. The magnitude of the jump lies typically in the range from $10^{10}$ to $10^{20}$. Because of this jump, the solutions $\psi, \eta$ and $\rho$ have thin interior layers in a neighbourhood of the $p-n$ junction.

In the numerical solution of this coupled nonlinear system, the iterative method of Gummel [2] is normally used to decouple the system. The result of this decoupling is that in each iteration the Poisson equation (1.1a) and the two continuity equations (1.1b), (1.1c) are solved sequentially. To solve the decoupled Poisson equation (1.1a), we apply the Newton iterative method to the nonlinear term $-\eta \mathrm{e}^{\psi}+\rho \mathrm{e}^{-\psi}$ which yields the following iterative process: given an initial guess $\psi_{0}$, for $k=0,1, \ldots$ until convergence, compute $\psi_{k+1}$ by solving the equation

$$
\psi_{k+1}^{\prime \prime}-\left(\eta \mathrm{e}^{\psi_{k}}+\rho \mathrm{e}^{-\psi_{k}}\right)\left(\psi_{k+1}-\psi_{k}\right)=\eta \mathrm{e}^{\psi_{k}}-\rho \mathrm{e}^{-\psi_{k}}-D
$$

with the Dirichlet boundary conditions

$$
\psi_{k+1}(0)=V_{0} \quad \text { and } \quad \psi_{k+1}(1)=V_{1},
$$

where $V_{0}$ and $V_{1}$ are the applied biases at the Ohmic contacts $x=0$ and $x=1$, respectively. As mentioned above, the solution to (1.2a) has a thin interior layer due to the jump in $D(x)$ at the $p-n$ junction. Furthermore, there are boundary layers in the solution $\psi_{k+1}$ at the boundary points 0 , 1 . In typical applications the applied (scaled) biases $V_{0}$ and $V_{1}$ lie in the range $[0,130]$ and hence the coefficient $-\left(\eta \mathrm{e}^{\psi}+\rho \mathrm{e}^{-\psi}\right)$ of the term $\psi_{k+1}$ in $(1.2 \mathrm{a})$ can be much greater than one in magnitude. We, therefore, introduce the scaling factor

$$
\lambda=\frac{1}{\max _{0 \leqslant x \leqslant 1}\left(\eta \mathrm{e}^{\psi_{k}}+\rho \mathrm{e}^{-\psi_{k}}\right)} .
$$

Multiplying both sides of (1.2a) by $\lambda$ we have

$$
\lambda \psi_{k+1}^{\prime \prime}-A(x)\left(\psi_{k+1}-\psi_{k}\right)=F(x),
$$

where

$$
A(x)=\lambda\left(\eta \mathrm{e}^{\psi_{k}}+\rho \mathrm{e}^{-\psi_{k}}\right) \quad \text { and } \quad F(x)=\lambda\left(\eta \mathrm{e}^{\psi_{k}}-\rho \mathrm{e}^{-\psi_{k}}-D\right) .
$$

It is clear that $0 \leqslant A(x) \leqslant 1$ and that $\lambda$ is positive because both $\eta$ and $\rho$ are positive. Since $\lambda$ can also become small, it follows that (1.2) is a singularly perturbed problem with the singular perturbation parameter $\lambda$.

In this paper we want to focus on overcoming the numerical difficulties caused by the presence of boundary and interior layers in the exact solution of problem (1.2). Therefore, we investigate the numerical solution of a single singularly perturbed second order ordinary differential equation with a discontinuity in its inhomogeneous term. An appropriate singularly perturbed linear two-point boundary value model problem is introduced in the next section.

\section{Singularly perturbed problem}

Motivated by the discussion in the previous section, we now consider the following singularly perturbed two point boundary value problem: 
Find $u_{\varepsilon} \in C^{1}(\bar{\Omega}) \cap C^{2}(\Omega \backslash\{d\})$ such that

$$
\begin{array}{ll}
-\varepsilon u_{\varepsilon}^{\prime \prime}+a(x) u_{\varepsilon}=f(x), & x \in \Omega \backslash\{d\}, \\
u(0)=u_{0}, & u(1)=u_{1}, \\
f(d-) \neq f(d+), &
\end{array}
$$

where $0<\varepsilon \leqslant 1$ is a singular perturbation parameter and $\alpha \leqslant a(x) \leqslant \alpha^{\prime}$ for some positive constants $\alpha$ and $\alpha^{\prime}$. We regard (2.1) as a model problem for (1.2), where $d$ corresponds to the location of the $p-n$ junction.

The solution $u_{\varepsilon}$ of problem 2.1 can be decomposed into discontinuous regular and singular components

$$
u_{\varepsilon}=v_{\varepsilon}+w_{\varepsilon}
$$

where the regular component $v_{\varepsilon}$ is defined on $\Omega \backslash\{d\}$ as the solution of the two problems

$$
\begin{array}{ll}
-\varepsilon v_{\varepsilon}^{\prime \prime}+a(x) v_{\varepsilon}=f(x), & x \in(0, d), \\
v_{\varepsilon}(0)=\frac{f(0)}{a(0)}, & v_{\varepsilon}(d-)=\frac{f(d-)}{a(d)},
\end{array}
$$

and

$$
\begin{array}{ll}
-\varepsilon v_{\varepsilon}^{\prime \prime}+a(x) v_{\varepsilon}=f(x), & x \in(d, 1), \\
v_{\varepsilon}(d+)=\frac{f(d+)}{a(d)}, & v_{\varepsilon}(1)=\frac{f(1)}{a(1)}
\end{array}
$$

and, consequently, the singular component $w_{\varepsilon}$ satisfies

$$
\begin{array}{ll}
\varepsilon w_{\varepsilon}^{\prime \prime}+a(x) w_{\varepsilon}=0, & x \in(0, d) \cup(d, 1), \\
w_{\varepsilon}(0)=u_{\varepsilon}(0)-v_{\varepsilon}(0), & w_{\varepsilon}(1)=u_{\varepsilon}(1)-v_{\varepsilon}(1), \\
{\left[w_{\varepsilon}(d)\right]=-\left[v_{\varepsilon}(d)\right],} & {\left[w_{\varepsilon}^{\prime}(d)\right]=-\left[v_{\varepsilon}^{\prime}(d)\right],}
\end{array}
$$

where $[\omega](d)=\omega(d+)-\omega(d-)$ denotes the jump at $d$ in any function $\omega$. Note that, although $v_{\varepsilon}$ and $w_{\varepsilon}$ are undefined at the point $x=d$, their sum is defined and continuous at this point. Also if, by chance, $u_{\varepsilon}(0)=v_{\varepsilon}(0)$ then no boundary layer occurs at the end-point $x=0$ and similarly at the end-point $x=1$.

We now state a useful lemma, which provides information about the boundary and interior layers occurring in the solution of problem (2.1).

Lemma 1. Let $u_{\varepsilon}=v_{\varepsilon}+w_{\varepsilon}$ be the solution of problem (2.1) and $v_{\varepsilon}, w_{\varepsilon}$ its regular and singular components defined in (2.3) and (2.4), respectively. Then, for each integer $k$ satisfying $0 \leqslant k \leqslant 4$, we have

$$
\begin{aligned}
& \left|v_{\varepsilon}^{(k)}(x)\right| \leqslant \begin{cases}C\left(1+\varepsilon^{1-k / 2}\right), & x \in(0, d), \\
C\left(1+\varepsilon^{1-k / 2}\right), & x \in(d, 1),\end{cases} \\
& \left|w_{\varepsilon}^{(k)}(x)\right| \leqslant \begin{cases}C \varepsilon^{-k / 2} e_{1}(x), & x \in(0, d), \\
C \varepsilon^{-k / 2} e_{2}(x), & x \in(d, 1),\end{cases}
\end{aligned}
$$

where $C$ is a constant independent of the singular perturbation parameter $\varepsilon$ and

$$
\begin{aligned}
& e_{1}(x)=\mathrm{e}^{-x \sqrt{\alpha / \varepsilon}}+\mathrm{e}^{-(d-x) \sqrt{\alpha / \varepsilon}}, \\
& e_{2}(x)=\mathrm{e}^{-(x-d) \sqrt{\alpha / \varepsilon}}+\mathrm{e}^{-(1-x) \sqrt{\alpha / \varepsilon}} .
\end{aligned}
$$


Proof. See [1,4] for details. Here we outline the main argument. The following minimum principle is first established.

Suppose that a function $\omega \in C^{0}(\bar{\Omega}) \cap C^{2}(\Omega \backslash\{d\})$ satisfies

$$
\begin{array}{ll}
\omega(0) \geqslant 0, & \omega(1) \geqslant 0, \\
-\varepsilon \omega^{\prime \prime}(x)+a(x) \omega(x) \geqslant 0, & \text { for all } x \in \Omega \backslash\{d\}, \\
{[\omega](d)=0,} & {\left[\omega^{\prime}\right](d) \leqslant 0,}
\end{array}
$$

then

$$
\omega(x) \geqslant 0, \quad \text { for all } x \in \bar{\Omega} .
$$

From this, one easily establishes that $\left\|u_{\varepsilon}\right\|_{\bar{\Omega}} \leqslant C$. The bounds on $v_{\varepsilon}$ and $w_{\varepsilon}$ and their derivatives are then established using the arguments given in [4] for the problem

$$
\begin{array}{ll}
-\varepsilon u_{\varepsilon}^{\prime \prime}+a(x) u_{\varepsilon}=f(x), & x \in \Omega, \\
u(0)=u_{0}, & u(1)=u_{1}, \\
a, f \in C^{1}(0,1) &
\end{array}
$$

applied to the intervals $(0, d)$ and $(d, 1)$, separately.

These bounds on the derivatives of the components of the solution enable us to identify the location and the width of the layers that are present in the solution $u_{\varepsilon}$ of problem (2.1). We see that the gradients in the boundary layer function $e_{1}$ depend inversely on $\varepsilon$ in $\mathrm{O}(\sqrt{\varepsilon})$-neighborhoods of the end-point $x=0$ and of the point $x=d$. Outside these neighborhoods, the boundary layer function $e_{1}$ and its derivatives are negligible, since for all $x \geqslant k \sqrt{\varepsilon / \alpha} \ln \varepsilon^{-1}$ we have

$$
\mathrm{e}^{-x \sqrt{\alpha / \varepsilon}} \leqslant \varepsilon^{k} .
$$

Analogously, the boundary layer function $e_{2}$ has steep gradients for small values of $\varepsilon$ in $\mathrm{O}(\sqrt{\varepsilon})$ neighborhoods of the point $x=d$ and of the end-point $x=1$.

Since we have identified where the layers occur in the solution of problem (2.1), it is both natural and advisable to design a mesh with a significant proportion of its mesh points in these layer regions, in order to resolve the corresponding boundary and interior layers. This leads in a natural way to the introduction of fitted mesh methods, which is the topic of the next section.

\section{Fitted mesh methods}

We use the fitted mesh methods described in [3] for wide classes of problems. These are numerical methods with piecewise-uniform fitted meshes having their mesh points distributed so that the resulting numerical solutions resolve the boundary layers in the exact solution. An additional feature of these methods is that, in the case of fitted finite difference methods, the linear interpolants of the finite difference solutions yield global approximations that converge in the maximum norm to the exact solution at each point of the domain $\bar{\Omega}$. A parameter-uniform fitted mesh method satisfies a parameter-uniform 
error estimate in the maximum norm, and so the convergence is independent of the singular perturbation parameter. This is described formally in the following definition.

Definition. Suppose that for each value of $\varepsilon$ the exact solution $u_{\varepsilon}$ is approximated by a sequence of numerical solutions $\left\{\left(U_{\varepsilon}^{N}, \bar{\Omega}^{N}\right)\right\}_{N=1}^{\infty}$ where $U_{\varepsilon}^{N}$ is defined on the mesh $\bar{\Omega}^{N}=\left\{x_{i} \mid x_{0}=0, x_{N}=1\right\}_{i=0}^{N}$. Let $\bar{U}_{\varepsilon}^{N}$ denote the piecewise linear interpolant over $\bar{\Omega}$ of the discrete solution $U_{\varepsilon}^{N}$ on $\bar{\Omega}^{N}$. Then, the numerical solutions are said to converge $\varepsilon$-uniformly, if there exist a positive integer $N_{0}$, and positive numbers $C$ and $p$, where $N_{0}, C$ and $p$ are all independent of $N$ and $\varepsilon$, such that for all $N \geqslant N_{0}$

$$
\sup _{0<\varepsilon \leqslant 1}\left\|\bar{U}_{\varepsilon}-u_{\varepsilon}\right\|_{\infty, \bar{\Omega}} \leqslant C N^{-p},
$$

where $\|f\|_{\infty, \bar{\Omega}}=\max _{x \in \bar{\Omega}}|f(x)|$. Here $p$ is called the $\varepsilon$-uniform order of convergence and $C$ is the $\varepsilon$-uniform error constant.

The reader is referred to [3] and the references therein for more details about fitted mesh methods. In this paper, fitted mesh methods are constructed to solve problem (2.1). The resulting fitted finite difference method is solved numerically using a non-overlapping Schwarz iterative process.

To construct the fitted mesh $\bar{\Omega}_{\varepsilon}^{N}$ we decompose the domain $\bar{\Omega}$ into six subdomains

$$
\bar{\Omega}=\Omega_{1} \cup \Omega_{2} \cup \Omega_{3} \cup \Omega_{4} \cup \Omega_{5} \cup \Omega_{6},
$$

where

$$
\begin{array}{lll}
\Omega_{1}=\left[0, \sigma_{1}\right), & \Omega_{2}=\left[\sigma_{1}, d-\sigma_{1}\right), & \Omega_{3}=\left[d-\sigma_{1}, d\right), \\
\Omega_{4}=\left[d, d+\sigma_{2}\right), & \Omega_{5}=\left[d+\sigma_{2}, 1-\sigma_{2}\right), & \Omega_{6}=\left[1-\sigma_{2}, 1\right] .
\end{array}
$$

The transition points $\sigma_{1}, \sigma_{2}$ are chosen as in [5] to be

$$
\sigma_{1}=\min \left\{\frac{d}{4}, 2 \sqrt{\frac{\varepsilon}{\alpha}} \ln N\right\}, \quad \sigma_{2}=\min \left\{\frac{1-d}{4}, 2 \sqrt{\frac{\varepsilon}{\alpha}} \ln N\right\} .
$$

This particular choice of the transition points is crucial for the $\varepsilon$-uniform convergence of the numerical method. Note that the transition points depend on both the singular perturbation parameter $\varepsilon$ and on the number $N$ of mesh elements. In each of the six subdomains a uniform mesh is used. That is, $N / 8$ nodes are uniformly distributed in each of the layer subdomains $\Omega_{i}(i=1,3,4,6)$, and $N / 4$ nodes are uniformly distributed in each of the subdomains $\Omega_{2}, \Omega_{5}$. The resulting fitted mesh $\bar{\Omega}_{\varepsilon}^{N}$ on $\bar{\Omega}$ is in general a piecewise-uniform mesh. We note in passing that it becomes a uniform mesh in the case when $\varepsilon$ or $N$ is sufficiently large to ensure that $\sigma_{1}=d / 4, \sigma_{2}=(1-d) / 4$. Note that we have used six subdomains, because there are in general two boundary layers, one at $x=0$, the other at $x=1$, and one interior layer at $x=d$. If the boundary conditions happen to have values such that no boundary layer occurs at a boundary point, then the corresponding fine mesh subdomain at that point can be eliminated and the obvious modifications are made in the distribution of the mesh points. Of course no harm is done, apart from some unnecessary computational work, if all of the fine mesh subdomains in such cases are retained.

Problem (2.1) is now discretized and solved on the fitted mesh $\bar{\Omega}_{\varepsilon}^{N}$ using the following parameterrobust non-overlapping Schwarz iterative method: given an initial guess $u^{[0]}(d)$ for the unknown $u_{\varepsilon}(d)$, the algorithm is started by specifying 


$$
\begin{aligned}
& U^{[0]}(x)=0, \quad x \in(0, d) \cup(d, 1), \\
& U^{[0]}(0)=u_{0}, \quad U^{[0]}(d)=u^{[0]}(d), \quad U^{[0]}(1)=u_{1} .
\end{aligned}
$$

Then, for $k=1,2,3, \ldots$ we solve the following two finite difference subproblems for the mesh functions $U_{\ell}^{[k]}, U_{r}^{[k]}$ :

$$
\begin{array}{ll}
-\varepsilon \delta^{2} U_{\ell}^{[k]}+a\left(x_{i}\right) U_{\ell}^{[k]}=f\left(x_{i}\right), & 1<i<N / 2, \\
U_{\ell}^{[k]}(0)=U^{[k-1]}(0), & U_{\ell}^{[k]}(d)=U^{[k-1]}(d), \\
-\varepsilon \delta^{2} U_{r}^{[k]}+a\left(x_{i}\right) U_{r}^{[k]}=f\left(x_{i}\right), & 1<i<N / 2, \\
U_{r}^{[k]}(0)=U^{[k-1]}(d), & U_{r}^{[k]}(1)=U^{[k-1]}(1),
\end{array}
$$

where the second order centered finite difference operator is defined by

$$
\delta^{2} Z_{i} \equiv \frac{D^{+} Z_{i}-D^{-} Z_{i}}{\left(x_{i+1}-x_{i-1}\right) / 2}
$$

and the first order forward and backward finite difference operators by

$$
D^{+} Z_{i} \equiv \frac{Z_{i+1}-Z_{i}}{x_{i+1}-x_{i}}, \quad D^{-} Z_{i} \equiv \frac{Z_{i}-Z_{i-1}}{x_{i}-x_{i-1}} .
$$

After these two sub-problems are solved, the approximation to $u_{\varepsilon}(d)$ is updated using the average of the computed values at the two neighboring nodes of $d$. That is,

$$
U^{[k]}(d)=\frac{\left(U_{\ell}^{[k-1]}\left(x_{(N / 2)-1}\right)+U_{r}^{[k-1]}\left(x_{(N / 2)+1}\right)\right)}{2} .
$$

We define the $k$ th Schwarz approximation to $u_{\varepsilon}$ as

$$
U^{[k]}= \begin{cases}\bar{U}_{\ell}^{[k]}, & x<d, \\ \frac{U_{\ell}^{[k-1]}\left(x_{(N / 2)-1}\right)+U_{r}^{[k-1]}\left(x_{(N / 2)+1}\right)}{2}, & x=d, \\ \bar{U}_{r}^{[k]}, & x>d,\end{cases}
$$

where $\bar{U}_{\ell}^{[k]}$ is the linear interpolant of $U_{\ell}^{[k]}$ onto $[0, d]$.

This iterative process is repeated until successive iterates are sufficiently close at each point of $\bar{\Omega}_{\varepsilon}^{N}$, in the sense that they satisfy the stopping criterion

$$
\max _{0<i<N}\left|U^{[k]}\left(x_{i}\right)-U^{[k-1]}\left(x_{i}\right)\right|<10^{-10} .
$$

\section{Numerical experiments}

To verify the effectiveness of the numerical method constructed in the previous section, we apply it to the following two test problems. Both test problems have one interior and one boundary layer. All the computations were performed in Fortran 77 double precision on a Pentium PC under the Linux environment. 
The first test problem is the reaction-diffusion problem

$$
\begin{aligned}
& -\varepsilon u_{\varepsilon}^{\prime \prime}+u_{\varepsilon}=f(x) \quad \text { in }(0,1), \\
& u_{\varepsilon}(0)=u_{\varepsilon}(1)=f(0),
\end{aligned}
$$

where

$$
f(x)= \begin{cases}-0.5 x, & x \leqslant 0.5 \\ 0.5, & x>0.5\end{cases}
$$

The solution $u_{\varepsilon}$ of this problem, which has an interior layer at $x=0.5$ and a boundary layer at $x=1$ is

$$
u_{\varepsilon}(x)=0.25(A+B)\left[\exp \left(-\frac{1}{\sqrt{\varepsilon}}(0.5-x)\right)-\exp \left(-\frac{1}{\sqrt{\varepsilon}}(0.5+x)\right)\right]-0.5 x
$$

for $x \leqslant 0.5$ and

$$
\begin{aligned}
u_{\varepsilon}(x)= & 0.25(A-B) \exp \left(-\frac{1}{2 \sqrt{\varepsilon}}\right)\left[\exp \left(-\frac{1}{\sqrt{\varepsilon}}(x-1)\right)-\exp \left(-\frac{1}{\sqrt{\varepsilon}}(1-x)\right)\right] \\
& +0.5\left(1-\exp \left(-\frac{1}{\sqrt{\varepsilon}}(1-x)\right)\right)
\end{aligned}
$$

for $x \geqslant 0.5$, where the constants $A$ and $B$ are

$$
A=\frac{\sqrt{\varepsilon}-\exp (-1 /(2 \sqrt{\varepsilon}))}{1+\exp (-1 / \sqrt{\varepsilon})} \quad \text { and } \quad B=\frac{1.5-\exp (-1 /(2 \sqrt{\varepsilon}))}{1-\exp (-1 / \sqrt{\varepsilon})} .
$$

Since the solution of this (and the next) problem has no boundary layer at the end-point $x=0$, the general algorithm described in the previous section may be appropriately modified. Hence, we decompose $\bar{\Omega}$ into the five subdomains

$$
[0,0.5-\sigma) \cup[0.5-\sigma, 0.5) \cup[0.5,0.5+\sigma) \cup[0.5+\sigma, 1-\sigma) \cup[1-\sigma, 1] .
$$

Then $N / 4$ mesh points are distributed uniformly in the subdomain $[0.5+\sigma, 1-\sigma), N / 8$ mesh points in each of the subdomains $[0.5-\sigma, 0.5),[0.5,0.5+\sigma)[1-\sigma, 1]$ and the remaining $3 N / 8$ mesh points in the subdomain $[0,0.5-\sigma)$.

The transition parameters are taken to be

$$
\sigma=\min \left\{\frac{1}{8}, 2 \sqrt{\varepsilon} \ln N\right\} .
$$

The problem is solved for various values of $\varepsilon$ and $N$ and the numerical results for four different values of $\varepsilon$ are plotted in Fig. 1. The initial guess $u^{[0]}(0.5)$ for $u_{\varepsilon}(0.5)$ is chosen in the following way: for each possible value of $\varepsilon$, the starting value for the first iterate for $u_{\varepsilon}(0.5)$ on the coarsest mesh is the average value of $f(x)$ at the two neighboring mesh points on either side of $x=0.5$. For subsequent iterates the computed value $U^{[k]}(0.5)$ on this mesh is then used as an initial guess for the next refined mesh. Since the exact solution has the simple closed form (4.2) the errors in the numerical solution can be computed exactly. The error in the maximum norm and the number of Schwarz iterations required for convergence are listed in Table 1 . The results confirm computationally that this method is $\varepsilon$-uniform. In Table 2 the errors in the maximum norm and the number of Schwarz iterations required for convergence using a 


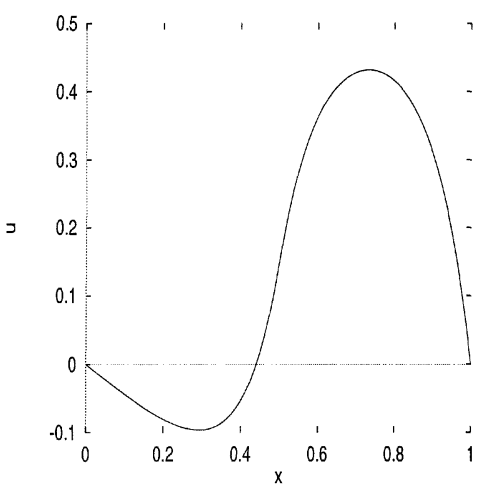

(a) $\varepsilon=10^{-2}$

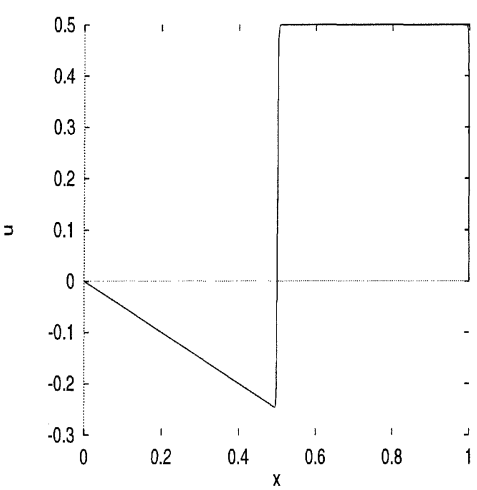

(c) $\varepsilon=10^{-6}$

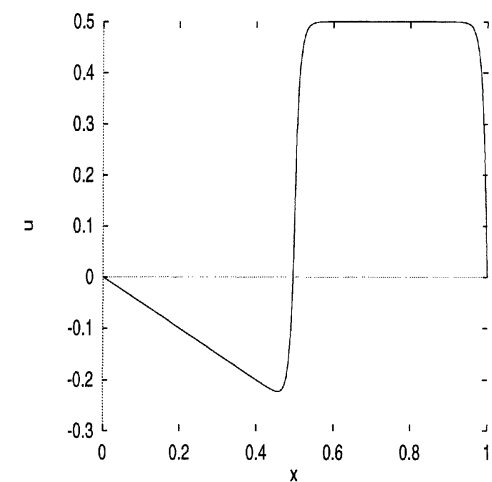

(b) $\varepsilon=10^{-4}$

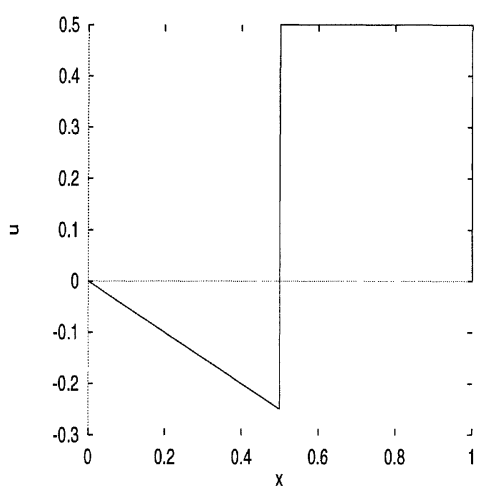

(d) $\varepsilon=10^{-8}$

Fig. 1. Graphs of the numerical solution of problem (4.1) for various values of $\varepsilon$ using method (3.1)-(3.5) with $N=80$.

uniform mesh on the whole of $\bar{\Omega}$ (i.e., $\varepsilon=\frac{1}{8}$ ) are given for comparison purposes, from which it is clear that this method is not $\varepsilon$-uniform.

Remark. The simpler initial guess strategy

$$
u^{[0]}(0.5)=\frac{f(0.5-)+f(0.5+)}{2}
$$

for all values of $N$ and $\varepsilon$ results in larger iteration counts. The numerical results corresponding to this simpler strategy are given in Table 3.

The second test problem is the reaction-diffusion problem with a nonsmooth variable coefficient

$$
\begin{aligned}
& -\varepsilon u^{\prime \prime}+a(x) u=f(x) \quad \text { in }(0,1), \\
& u(0)=u(1)=f(0),
\end{aligned}
$$

where

$$
a(x)=\left\{\begin{array}{ll}
2 x+1, & x \leqslant 0.5, \\
2(1-x)+1, & x>0.5
\end{array} \text { and } \quad f(x)= \begin{cases}-0.5, & x \leqslant 0.5 \\
0.5, & x>0.5\end{cases}\right.
$$


Table 1

Maximum pointwise errors and iteration counts for method (3.1)-(3.5) applied to problem (4.1) for various values of $\varepsilon$ and $N$

\begin{tabular}{|c|c|c|c|c|c|c|c|c|}
\hline$\varepsilon \backslash N$ & 8 & 16 & 32 & 64 & 128 & 256 & 512 & 1024 \\
\hline \multirow[t]{2}{*}{1} & $3.78 \mathrm{E}-3$ & $1.66 \mathrm{E}-3$ & $7.95 \mathrm{E}-4$ & $3.90 \mathrm{E}-4$ & $1.93 \mathrm{E}-4$ & $9.63 \mathrm{E}-5$ & $4.80 \mathrm{E}-5$ & $2.40 \mathrm{E}-5$ \\
\hline & 65 & 105 & 192 & 347 & 613 & 1064 & 1801 & 2948 \\
\hline \multirow[t]{2}{*}{$2^{-2}$} & $9.42 \mathrm{E}-3$ & $3.75 \mathrm{E}-3$ & $1.72 \mathrm{E}-3$ & $8.25 \mathrm{E}-4$ & $4.05 \mathrm{E}-4$ & $2.01 \mathrm{E}-04$ & $9.99 \mathrm{E}-5$ & $4.98 \mathrm{E}-5$ \\
\hline & 55 & 95 & 173 & 311 & 553 & 969 & 1666 & 2791 \\
\hline \multirow[t]{2}{*}{$2^{-4}$} & $9.49 \mathrm{E}-3$ & $2.06 \mathrm{E}-3$ & $6.45 \mathrm{E}-4$ & $2.49 \mathrm{E}-4$ & $1.08 \mathrm{E}-4$ & $5.04 \mathrm{E}-5$ & $2.43 \mathrm{E}-5$ & $1.19 \mathrm{E}-5$ \\
\hline & 35 & 65 & 112 & 193 & 332 & 565 & 946 & 1535 \\
\hline \multirow[t]{2}{*}{$2^{-6}$} & $8.39 \mathrm{E}-3$ & $4.86 \mathrm{E}-3$ & $2.69 \mathrm{E}-3$ & $1.37 \mathrm{E}-3$ & $6.89 \mathrm{E}-4$ & $3.45 \mathrm{E}-4$ & $1.72 \mathrm{E}-4$ & $8.62 \mathrm{E}-5$ \\
\hline & 21 & 33 & 63 & 116 & 208 & 372 & 653 & 1129 \\
\hline \multirow[t]{2}{*}{$2^{-8}$} & $1.89 \mathrm{E}-2$ & $9.09 \mathrm{E}-3$ & $4.29 \mathrm{E}-3$ & $2.04 \mathrm{E}-3$ & $9.95 \mathrm{E}-4$ & $4.90 \mathrm{E}-4$ & $2.43 \mathrm{E}-4$ & $1.21 \mathrm{E}-4$ \\
\hline & 12 & 20 & 35 & 63 & 114 & 204 & 361 & 632 \\
\hline \multirow[t]{2}{*}{$2^{-10}$} & $2.32 \mathrm{E}-2$ & $1.81 \mathrm{E}-2$ & $7.23 \mathrm{E}-3$ & $2.52 \mathrm{E}-3$ & $1.04 \mathrm{E}-3$ & $5.04 \mathrm{E}-4$ & $2.43 \mathrm{E}-04$ & $1.21 \mathrm{E}-4$ \\
\hline & 8 & 12 & 20 & 34 & 61 & 108 & 193 & 339 \\
\hline \multirow[t]{2}{*}{$2^{-12}$} & $1.22 \mathrm{E}-2$ & $2.08 \mathrm{E}-2$ & $1.59 \mathrm{E}-2$ & $7.04 \mathrm{E}-3$ & $1.87 \mathrm{E}-3$ & $6.12 \mathrm{E}-4$ & $2.52 \mathrm{E}-4$ & $1.24 \mathrm{E}-4$ \\
\hline & 7 & 9 & 12 & 19 & 33 & 58 & 103 & 182 \\
\hline \multirow[t]{2}{*}{$2^{-14}$} & $6.11 \mathrm{E}-3$ & $2.06 \mathrm{E}-2$ & $1.59 \mathrm{E}-2$ & $7.57 \mathrm{E}-3$ & $2.68 \mathrm{E}-3$ & $9.10 \mathrm{E}-4$ & $3.05 \mathrm{E}-4$ & $1.22 \mathrm{E}-4$ \\
\hline & 6 & 9 & 12 & 17 & 26 & 41 & 66 & 107 \\
\hline \multirow[t]{2}{*}{$2^{-16}$} & $4.09 \mathrm{E}-3$ & $2.05 \mathrm{E}-2$ & $1.59 \mathrm{E}-2$ & $7.57 \mathrm{E}-3$ & $2.68 \mathrm{E}-3$ & $9.10 \mathrm{E}-4$ & $2.90 \mathrm{E}-4$ & $9.07 \mathrm{E}-5$ \\
\hline & 5 & 9 & 12 & 17 & 25 & 39 & 63 & 101 \\
\hline \multirow[t]{2}{*}{$2^{-18}$} & $5.94 \mathrm{E}-3$ & $2.04 \mathrm{E}-2$ & $1.59 \mathrm{E}-2$ & $7.57 \mathrm{E}-3$ & $2.68 \mathrm{E}-3$ & $9.10 \mathrm{E}-4$ & $2.90 \mathrm{E}-4$ & $8.98 E-5$ \\
\hline & 5 & 8 & 11 & 16 & 24 & 37 & 59 & 94 \\
\hline \multirow[t]{2}{*}{$2^{-20}$} & $6.88 \mathrm{E}-3$ & $2.04 \mathrm{E}-2$ & $1.59 \mathrm{E}-2$ & $7.57 \mathrm{E}-3$ & $2.68 \mathrm{E}-3$ & $9.10 \mathrm{E}-4$ & $2.90 \mathrm{E}-4$ & $8.98 \mathrm{E}-5$ \\
\hline & 4 & 8 & 11 & 15 & 23 & 35 & 56 & 88 \\
\hline \multirow[t]{2}{*}{$2^{-22}$} & $7.34 \mathrm{E}-3$ & $2.04 \mathrm{E}-2$ & $1.59 \mathrm{E}-2$ & $7.57 \mathrm{E}-3$ & $2.68 \mathrm{E}-3$ & $9.10 \mathrm{E}-4$ & $2.90 \mathrm{E}-4$ & $8.98 \mathrm{E}-5$ \\
\hline & 4 & 8 & 10 & 14 & 22 & 33 & 52 & 82 \\
\hline \multirow[t]{2}{*}{$2^{-24}$} & $7.58 \mathrm{E}-3$ & $2.04 \mathrm{E}-2$ & $1.59 \mathrm{E}-2$ & $7.57 \mathrm{E}-3$ & $2.68 \mathrm{E}-3$ & $9.10 \mathrm{E}-4$ & $2.90 \mathrm{E}-4$ & $8.98 \mathrm{E}-5$ \\
\hline & 3 & 7 & 10 & 14 & 20 & 31 & 48 & 75 \\
\hline
\end{tabular}


Table 2

Maximum pointwise errors and iteration counts for method (3.1)-(3.5) with $\sigma=\frac{1}{8}$ applied to problem (4.1) for various values of $\varepsilon$ and $N$

\begin{tabular}{|c|c|c|c|c|c|c|c|c|}
\hline$\varepsilon \backslash N$ & 8 & 16 & 32 & 64 & 128 & 256 & 512 & 1024 \\
\hline \multirow[t]{2}{*}{1} & $2.43 E-3$ & $1.38 \mathrm{E}-3$ & $7.30 \mathrm{E}-4$ & $3.74 \mathrm{E}-4$ & $1.90 \mathrm{E}-4$ & $9.53 \mathrm{E}-5$ & $4.78 \mathrm{E}-5$ & $2.40 \mathrm{E}-5$ \\
\hline & 51 & 94 & 183 & 338 & 605 & 1057 & 1795 & 2942 \\
\hline \multirow[t]{2}{*}{$2^{-2}$} & $4.18 \mathrm{E}-3$ & $2.67 E-3$ & $1.47 \mathrm{E}-3$ & $7.65 \mathrm{E}-4$ & $3.90 \mathrm{E}-4$ & $1.97 \mathrm{E}-4$ & $9.90 \mathrm{E}-5$ & $4.96 \mathrm{E}-5$ \\
\hline & 47 & 82 & 162 & 301 & 543 & 960 & 1658 & 2783 \\
\hline \multirow[t]{2}{*}{$2^{-4}$} & $7.19 \mathrm{E}-3$ & $1.30 \mathrm{E}-3$ & $1.36 \mathrm{E}-4$ & $6.83 \mathrm{E}-5$ & $6.39 \mathrm{E}-5$ & $3.94 \mathrm{E}-5$ & $2.15 \mathrm{E}-5$ & $1.12 \mathrm{E}-5$ \\
\hline & 34 & 61 & 107 & 178 & 217 & 510 & 897 & 1489 \\
\hline \multirow[t]{2}{*}{$2^{-6}$} & $3.82 \mathrm{E}-2$ & $1.23 \mathrm{E}-2$ & $4.39 \mathrm{E}-3$ & $1.78 \mathrm{E}-3$ & $7.88 \mathrm{E}-4$ & $3.69 \mathrm{E}-4$ & $1.78 \mathrm{E}-4$ & $8.77 \mathrm{E}-5$ \\
\hline & 20 & 37 & 66 & 119 & 213 & 376 & 659 & 1134 \\
\hline \multirow[t]{2}{*}{$2^{-8}$} & $6.53 \mathrm{E}-2$ & $2.20 \mathrm{E}-2$ & $7.50 \mathrm{E}-3$ & $2.83 E-3$ & $1.19 \mathrm{E}-3$ & $5.38 \mathrm{E}-4$ & $2.55 \mathrm{E}-4$ & $1.24 \mathrm{E}-4$ \\
\hline & 12 & 21 & 37 & 65 & 117 & 207 & 365 & 636 \\
\hline \multirow[t]{2}{*}{$2^{-10}$} & $7.87 \mathrm{E}-2$ & $3.02 \mathrm{E}-2$ & $1.06 \mathrm{E}-2$ & $3.70 \mathrm{E}-3$ & $1.42 \mathrm{E}-3$ & $5.98 \mathrm{E}-4$ & $2.71 \mathrm{E}-4$ & $1.29 \mathrm{E}-4$ \\
\hline & 8 & 12 & 20 & 36 & 63 & 111 & 196 & 343 \\
\hline \multirow[t]{2}{*}{$2^{-12}$} & $8.46 \mathrm{E}-2$ & $3.63 \mathrm{E}-2$ & $1.81 \mathrm{E}-2$ & $7.57 \mathrm{E}-3$ & $2.32 \mathrm{E}-3$ & $7.43 \mathrm{E}-4$ & $2.98 \mathrm{E}-4$ & $1.36 \mathrm{E}-4$ \\
\hline & 6 & 8 & 12 & 20 & 34 & 60 & 106 & 185 \\
\hline \multirow[t]{2}{*}{$2^{-14}$} & $8.71 \mathrm{E}-2$ & $3.93 \mathrm{E}-2$ & $1.87 \mathrm{E}-2$ & $1.81 \mathrm{E}-2$ & $7.04 \mathrm{E}-3$ & $1.87 \mathrm{E}-3$ & $5.14 \mathrm{E}-4$ & $1.66 \mathrm{E}-4$ \\
\hline & 5 & 6 & 8 & 12 & 19 & 33 & 58 & 100 \\
\hline \multirow[t]{2}{*}{$2^{-16}$} & $8.83 \mathrm{E}-2$ & $4.06 \mathrm{E}-2$ & $1.90 \mathrm{E}-2$ & $1.87 \mathrm{E}-2$ & $1.81 \mathrm{E}-2$ & $7.04 \mathrm{E}-3$ & $1.87 \mathrm{E}-3$ & $4.76 \mathrm{E}-4$ \\
\hline & 4 & 5 & 6 & 8 & 11 & 19 & 32 & 55 \\
\hline \multirow[t]{2}{*}{$2^{-18}$} & $8.88 \mathrm{E}-2$ & $4.12 \mathrm{E}-2$ & $1.96 \mathrm{E}-2$ & $9.32 \mathrm{E}-3$ & $1.87 \mathrm{E}-2$ & $1.81 \mathrm{E}-2$ & $7.04 \mathrm{E}-3$ & $1.87 \mathrm{E}-3$ \\
\hline & 4 & 4 & 5 & 6 & 8 & 11 & 18 & 30 \\
\hline \multirow[t]{2}{*}{$2^{-20}$} & $8.90 \mathrm{E}-2$ & $4.14 \mathrm{E}-2$ & $1.99 \mathrm{E}-2$ & $9.65 E-3$ & $7.41 \mathrm{E}-3$ & $1.87 \mathrm{E}-2$ & $1.81 \mathrm{E}-2$ & $7.04 \mathrm{E}-3$ \\
\hline & 4 & 4 & 4 & 5 & 6 & 7 & 11 & 17 \\
\hline \multirow[t]{2}{*}{$2^{-22}$} & $7.63 \mathrm{E}-6$ & $3.05 \mathrm{E}-5$ & $1.22 \mathrm{E}-4$ & $4.87 \mathrm{E}-4$ & $1.94 \mathrm{E}-3$ & $7.41 \mathrm{E}-3$ & $1.87 \mathrm{E}-2$ & $1.81 \mathrm{E}-2$ \\
\hline & 3 & 4 & 4 & 4 & 5 & 6 & 7 & 10 \\
\hline \multirow[t]{2}{*}{$2^{-24}$} & $1.91 \mathrm{E}-6$ & $7.63 \mathrm{E}-6$ & $3.05 \mathrm{E}-5$ & $1.22 \mathrm{E}-4$ & $4.87 \mathrm{E}-4$ & $1.94 \mathrm{E}-3$ & $7.41 \mathrm{E}-3$ & $1.87 \mathrm{E}-2$ \\
\hline & 3 & 3 & 3 & 4 & 4 & 5 & 5 & 7 \\
\hline
\end{tabular}


Table 3

Maximum pointwise errors and iteration counts for method (3.1)-(3.5) with the initial guess strategy (4.3) applied to problem (4.1) for various values of $\varepsilon$ and $N$

\begin{tabular}{|c|c|c|c|c|c|c|c|c|}
\hline$\varepsilon \backslash N$ & 8 & 16 & 32 & 64 & 128 & 256 & 512 & 1024 \\
\hline \multirow[t]{2}{*}{1} & $3.78 \mathrm{E}-3$ & $1.66 \mathrm{E}-3$ & $7.95 \mathrm{E}-4$ & $3.90 \mathrm{E}-4$ & $1.93 \mathrm{E}-4$ & $9.62 \mathrm{E}-5$ & $4.80 \mathrm{E}-5$ & $2.39 \mathrm{E}-5$ \\
\hline & 65 & 133 & 262 & 509 & 983 & 1889 & 3619 & 6916 \\
\hline \multirow[t]{2}{*}{$2^{-2}$} & $9.42 \mathrm{E}-3$ & $3.75 \mathrm{E}-3$ & $1.725 \mathrm{E}-3$ & $8.25 \mathrm{E}-4$ & $4.05 \mathrm{E}-4$ & $2.02 \mathrm{E}-4$ & $9.98 \mathrm{E}-5$ & $4.98 \mathrm{E}-5$ \\
\hline & 55 & 110 & 215 & 415 & 799 & 1533 & 2932 & 5596 \\
\hline \multirow[t]{2}{*}{$2^{-4}$} & $9.49 \mathrm{E}-3$ & $2.06 \mathrm{E}-3$ & $6.45 \mathrm{E}-4$ & $2.49 \mathrm{E}-4$ & $1.08 \mathrm{E}-4$ & $5.03 \mathrm{E}-5$ & $2.42 \mathrm{E}-5$ & $1.19 \mathrm{E}-5$ \\
\hline & 35 & 66 & 124 & 236 & 449 & 854 & 1621 & 3070 \\
\hline \multirow[t]{2}{*}{$2^{-6}$} & $8.39 \mathrm{E}-3$ & $4.86 \mathrm{E}-3$ & $2.69 \mathrm{E}-3$ & $1.37 \mathrm{E}-3$ & $6.89 \mathrm{E}-4$ & $3.45 \mathrm{E}-4$ & $1.72 \mathrm{E}-4$ & $8.62 \mathrm{E}-5$ \\
\hline & 21 & 39 & 73 & 139 & 264 & 505 & 964 & 1838 \\
\hline \multirow[t]{2}{*}{$2^{-8}$} & $1.89 \mathrm{E}-2$ & $9.09 \mathrm{E}-3$ & $4.29 \mathrm{E}-3$ & $2.04 \mathrm{E}-3$ & $9.95 \mathrm{E}-4$ & $4.90 \mathrm{E}-4$ & $2.43 \mathrm{E}-4$ & $1.21 \mathrm{E}-4$ \\
\hline & 12 & 21 & 38 & 72 & 136 & 259 & 494 & 942 \\
\hline \multirow[t]{2}{*}{$2^{-10}$} & $2.32 \mathrm{E}-02$ & $1.81 \mathrm{E}-2$ & $7.23 \mathrm{E}-3$ & $2.52 \mathrm{E}-3$ & $1.04 \mathrm{E}-3$ & $5.04 \mathrm{E}-4$ & $2.48 \mathrm{E}-4$ & $1.23 \mathrm{E}-4$ \\
\hline & 8 & 12 & 20 & 37 & 69 & 130 & 248 & 472 \\
\hline \multirow[t]{2}{*}{$2^{-12}$} & $1.22 \mathrm{E}-2$ & $2.08 \mathrm{E}-2$ & $1.59 \mathrm{E}-2$ & $7.04 \mathrm{E}-3$ & $1.87 \mathrm{E}-3$ & $6.12 \mathrm{E}-4$ & $2.52 \mathrm{E}-4$ & $1.24 \mathrm{E}-4$ \\
\hline & 7 & 10 & 13 & 20 & 35 & 66 & 125 & 237 \\
\hline \multirow[t]{2}{*}{$2^{-14}$} & $6.12 \mathrm{E}-3$ & $2.06 \mathrm{E}-02$ & $1.59 \mathrm{E}-2$ & $7.57 \mathrm{E}-3$ & $2.68 \mathrm{E}-03$ & $9.10 \mathrm{E}-4$ & $3.05 \mathrm{E}-4$ & $1.22 \mathrm{E}-4$ \\
\hline & 6 & 9 & 13 & 18 & 29 & 47 & 79 & 136 \\
\hline \multirow[t]{2}{*}{$2^{-16}$} & $4.09 \mathrm{E}-3$ & $2.05 \mathrm{E}-02$ & $1.59 \mathrm{E}-2$ & $7.57 \mathrm{E}-3$ & $2.68 \mathrm{E}-3$ & $9.10 \mathrm{E}-4$ & $2.90 \mathrm{E}-4$ & $9.07 \mathrm{E}-5$ \\
\hline & 5 & 9 & 12 & 18 & 28 & 45 & 76 & 130 \\
\hline \multirow[t]{2}{*}{$2^{-18}$} & $5.94 \mathrm{E}-3$ & $2.04 \mathrm{E}-2$ & $1.59 \mathrm{E}-2$ & $7.57 \mathrm{E}-3$ & $2.68 \mathrm{E}-3$ & $9.10 \mathrm{E}-4$ & $2.90 \mathrm{E}-4$ & $8.98 \mathrm{E}-5$ \\
\hline & 5 & 9 & 12 & 17 & 26 & 43 & 72 & 123 \\
\hline \multirow[t]{2}{*}{$2^{-20}$} & $6.88 \mathrm{E}-3$ & $2.04 \mathrm{E}-2$ & $1.59 \mathrm{E}-2$ & $7.57 \mathrm{E}-3$ & $2.68 \mathrm{E}-03$ & $9.10 \mathrm{E}-4$ & $2.90 \mathrm{E}-4$ & $8.98 \mathrm{E}-5$ \\
\hline & 4 & 8 & 11 & 16 & 25 & 41 & 69 & 117 \\
\hline \multirow[t]{2}{*}{$2^{-22}$} & $7.34 \mathrm{E}-3$ & $2.04 \mathrm{E}-02$ & $1.59 \mathrm{E}-2$ & $7.57 \mathrm{E}-3$ & $2.68 \mathrm{E}-03$ & $9.10 \mathrm{E}-4$ & $2.90 \mathrm{E}-4$ & $8.98 \mathrm{E}-5$ \\
\hline & 4 & 8 & 11 & 16 & 24 & 39 & 65 & 110 \\
\hline \multirow[t]{2}{*}{$2^{-24}$} & $7.58 \mathrm{E}-3$ & $2.04 \mathrm{E}-2$ & $1.59 \mathrm{E}-2$ & $7.57 \mathrm{E}-3$ & $2.68 \mathrm{E}-03$ & $9.10 \mathrm{E}-4$ & $2.90 \mathrm{E}-4$ & $8.98 \mathrm{E}-5$ \\
\hline & 3 & 8 & 10 & 15 & 23 & 37 & 62 & 104 \\
\hline
\end{tabular}




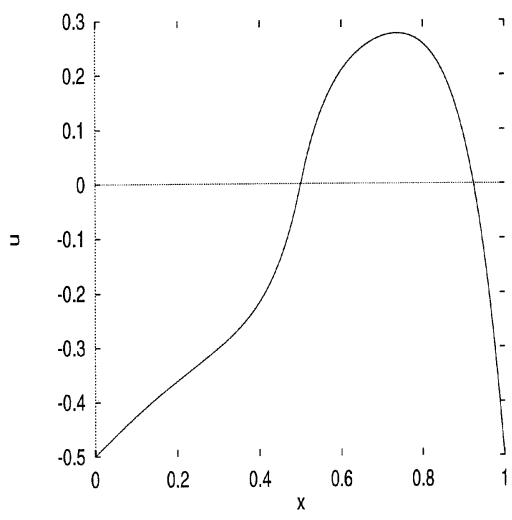

(a) $\varepsilon=10^{-2}$

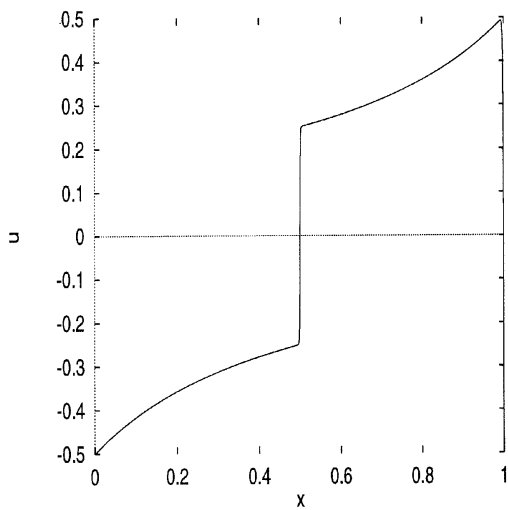

(c) $\varepsilon=10^{-6}$

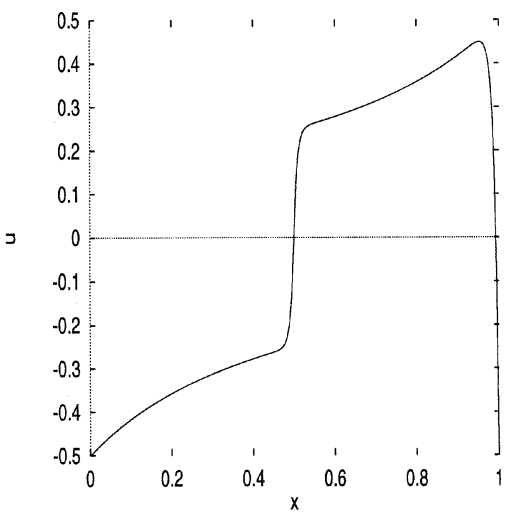

(b) $\varepsilon=10^{-4}$

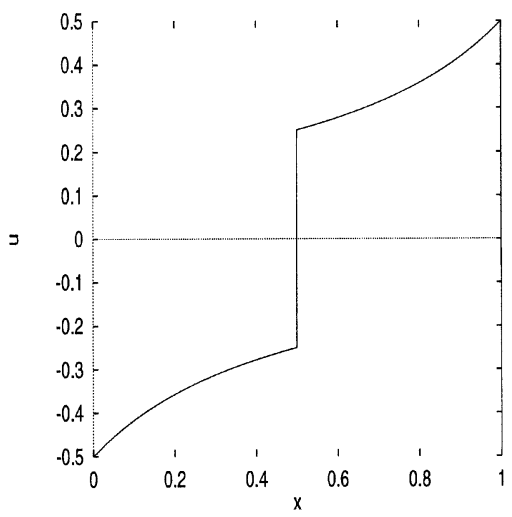

(d) $\varepsilon=10^{-8}$

Fig. 2. Graphs of the numerical solution of problem (4.4) for various values of $\varepsilon$ using method (3.1)-(3.5) with $N=80$.

This test problem is solved using the same techniques as for the first. Graphs of the corresponding numerical solutions are shown in Fig. 2. However, in this case a simple closed form of the exact solution is not available and so we need to estimate the errors in the numerical solutions by taking as an approximate exact solution the numerical solutions obtained on the fitted mesh $\Omega_{\varepsilon}^{6000}$. When the point $x$ is not a mesh point, we use the linear interpolant of the values at the two neighboring mesh points. The computed error in the maximum norm and number of Schwarz iterates required for convergence are given in Table 4 . The results confirm computationally that this is an $\varepsilon$-uniform method for the sake of comparison, analogous results using a single uniform mesh on the whole of $\bar{\Omega}$, obtained by taking $\sigma=\frac{1}{8}$, are shown in Table 5 . It is clear that the latter is not an $\varepsilon$-uniform method.

\section{Conclusions}

From the numerical experiments conducted in the previous section, we see that our new numerical method, consisting of a standard finite difference operator on a non-standard piecewise-uniform fitted 
Table 4

Computed maximum pointwise errors and iteration counts for method (3.1)-(3.5) applied to problem (4.4) for various values of $\varepsilon$ and $N$

\begin{tabular}{|c|c|c|c|c|c|c|c|}
\hline$\varepsilon \backslash N$ & 12 & 24 & 48 & 96 & 192 & 384 & 768 \\
\hline \multirow[t]{2}{*}{1} & $1.82 \mathrm{E}-2$ & $9.05 \mathrm{E}-3$ & $3.98 \mathrm{E}-3$ & $1.87 \mathrm{E}-3$ & $9.18 \mathrm{E}-4$ & $4.44 \mathrm{E}-4$ & $2.05 \mathrm{E}-4$ \\
\hline & 85 & 138 & 287 & 544 & 966 & 1704 & 2969 \\
\hline \multirow[t]{2}{*}{$4^{-1}$} & $3.73 \mathrm{E}-2$ & $1.77 \mathrm{E}-2$ & $7.59 \mathrm{E}-3$ & $3.52 \mathrm{E}-3$ & $1.72 E-3$ & 8.30E-4 & $3.83 E-4$ \\
\hline & 64 & 112 & 231 & 437 & 780 & 1387 & 2445 \\
\hline \multirow[t]{2}{*}{$4^{-2}$} & $3.14 \mathrm{E}-2$ & $1.34 \mathrm{E}-2$ & $5.44 \mathrm{E}-3$ & $2.46 \mathrm{E}-3$ & $1.19 \mathrm{E}-3$ & $5.70 \mathrm{E}-4$ & $2.63 \mathrm{E}-4$ \\
\hline & 40 & 67 & 134 & 251 & 447 & 795 & 1402 \\
\hline \multirow[t]{2}{*}{$4^{-3}$} & $1.30 \mathrm{E}-2$ & $3.42 \mathrm{E}-3$ & $1.03 \mathrm{E}-3$ & $4.40 \mathrm{E}-4$ & $2.06 \mathrm{E}-4$ & $9.74 \mathrm{E}-5$ & $4.46 \mathrm{E}-5$ \\
\hline & 21 & 33 & 64 & 117 & 205 & 358 & 620 \\
\hline \multirow[t]{2}{*}{$4^{-4}$} & $2.68 \mathrm{E}-2$ & $7.99 \mathrm{E}-3$ & $1.69 \mathrm{E}-3$ & $3.81 \mathrm{E}-4$ & $9.54 \mathrm{E}-5$ & $2.37 \mathrm{E}-5$ & $5.80 \mathrm{E}-6$ \\
\hline & 11 & 16 & 27 & 45 & 74 & 120 & 189 \\
\hline \multirow[t]{2}{*}{$4^{-5}$} & $3.75 \mathrm{E}-2$ & $2.71 \mathrm{E}-2$ & $6.53 \mathrm{E}-3$ & $1.60 \mathrm{E}-3$ & $4.01 \mathrm{E}-4$ & $9.92 \mathrm{E}-5$ & $2.41 \mathrm{E}-5$ \\
\hline & 6 & 7 & 8 & 9 & 6 & 1 & 1 \\
\hline \multirow[t]{2}{*}{$4^{-6}$} & $3.82 \mathrm{E}-2$ & $2.79 \mathrm{E}-2$ & $1.01 \mathrm{E}-2$ & $3.33 \mathrm{E}-3$ & $1.11 \mathrm{E}-3$ & $3.57 \mathrm{E}-4$ & $1.01 \mathrm{E}-4$ \\
\hline & 5 & 7 & 6 & 1 & 1 & 1 & 1 \\
\hline \multirow[t]{2}{*}{$4^{-7}$} & $3.86 \mathrm{E}-2$ & $2.83 \mathrm{E}-2$ & $1.03 \mathrm{E}-2$ & $3.39 \mathrm{E}-3$ & $1.13 \mathrm{E}-3$ & $3.57 \mathrm{E}-4$ & $1.06 \mathrm{E}-4$ \\
\hline & 5 & 7 & 6 & 1 & 1 & 1 & 1 \\
\hline \multirow[t]{2}{*}{$4^{-8}$} & $3.88 \mathrm{E}-2$ & $2.86 \mathrm{E}-2$ & $1.04 \mathrm{E}-2$ & $3.42 \mathrm{E}-3$ & $1.14 \mathrm{E}-3$ & $3.61 \mathrm{E}-4$ & $1.07 \mathrm{E}-4$ \\
\hline & 5 & 7 & 6 & 1 & 1 & 1 & 1 \\
\hline \multirow[t]{2}{*}{$4^{-9}$} & $3.89 \mathrm{E}-2$ & $2.87 \mathrm{E}-2$ & $1.05 \mathrm{E}-2$ & $3.44 \mathrm{E}-3$ & $1.14 \mathrm{E}-3$ & $3.63 \mathrm{E}-4$ & $1.08 \mathrm{E}-4$ \\
\hline & 5 & 6 & 5 & 1 & 1 & 1 & 1 \\
\hline \multirow[t]{2}{*}{$4^{-10}$} & $3.89 \mathrm{E}-2$ & $2.88 \mathrm{E}-2$ & $1.05 \mathrm{E}-2$ & $3.44 \mathrm{E}-3$ & $1.15 \mathrm{E}-3$ & $3.64 \mathrm{E}-4$ & $1.08 \mathrm{E}-4$ \\
\hline & 5 & 6 & 5 & 1 & 1 & 1 & 1 \\
\hline \multirow[t]{2}{*}{$4^{-11}$} & $3.90 \mathrm{E}-2$ & $2.88 \mathrm{E}-2$ & $1.05 \mathrm{E}-2$ & $3.45 \mathrm{E}-3$ & $1.15 \mathrm{E}-3$ & $3.64 \mathrm{E}-4$ & $1.08 \mathrm{E}-4$ \\
\hline & 4 & 5 & 4 & 1 & 1 & 1 & 1 \\
\hline \multirow[t]{2}{*}{$4^{-12}$} & $3.90 \mathrm{E}-2$ & $2.88 \mathrm{E}-2$ & $1.05 \mathrm{E}-2$ & $3.45 \mathrm{E}-3$ & $1.15 \mathrm{E}-3$ & $3.64 \mathrm{E}-4$ & $1.08 \mathrm{E}-4$ \\
\hline & 4 & 5 & 3 & 1 & 1 & 1 & 1 \\
\hline
\end{tabular}


Table 5

Computed maximum pointwise errors and iteration counts for method (3.1)-(3.5) with $\sigma=$ $1 / 8$ applied to problem (4.4) for various values of $\varepsilon$ and $N$

\begin{tabular}{|c|c|c|c|c|c|c|c|}
\hline$\varepsilon \backslash N$ & 12 & 24 & 48 & 96 & 192 & 384 & 768 \\
\hline \multirow[t]{2}{*}{1} & $1.57 \mathrm{E}-2$ & $7.65 E-3$ & $3.77 \mathrm{E}-3$ & $1.86 \mathrm{E}-3$ & $9.11 \mathrm{E}-4$ & $4.40 \mathrm{E}-4$ & $2.05 \mathrm{E}-4$ \\
\hline & 94 & 156 & 294 & 539 & 971 & 1715 & 2971 \\
\hline \multirow[t]{2}{*}{$4^{-1}$} & $3.10 \mathrm{E}-2$ & $1.47 \mathrm{E}-2$ & $7.11 \mathrm{E}-3$ & $3.48 \mathrm{E}-3$ & $1.70 \mathrm{E}-3$ & $8.21 \mathrm{E}-4$ & $3.82 \mathrm{E}-4$ \\
\hline & 70 & 127 & 236 & 433 & 783 & 1396 & 2447 \\
\hline \multirow[t]{2}{*}{$4^{-2}$} & $2.17 \mathrm{E}-2$ & $1.00 \mathrm{E}-2$ & $4.85 \mathrm{E}-3$ & $2.38 \mathrm{E}-3$ & $1.16 \mathrm{E}-3$ & $5.60 \mathrm{E}-4$ & $2.60 \mathrm{E}-4$ \\
\hline & 44 & 74 & 136 & 248 & 448 & 798 & 1402 \\
\hline \multirow[t]{2}{*}{$4^{-3}$} & $6.08 \mathrm{E}-3$ & $1.51 \mathrm{E}-3$ & $4.42 \mathrm{E}-4$ & $2.76 \mathrm{E}-4$ & $1.65 \mathrm{E}-4$ & $8.66 \mathrm{E}-5$ & $4.20 \mathrm{E}-5$ \\
\hline & 23 & 36 & 62 & 95 & 193 & 349 & 610 \\
\hline \multirow[t]{2}{*}{$4^{-4}$} & $2.04 \mathrm{E}-2$ & $5.72 \mathrm{E}-3$ & $1.55 \mathrm{E}-3$ & $3.81 \mathrm{E}-4$ & $9.31 \mathrm{E}-5$ & $2.31 \mathrm{E}-5$ & $5.70 \mathrm{E}-6$ \\
\hline & 13 & 21 & 36 & 63 & 108 & 179 & 286 \\
\hline \multirow[t]{2}{*}{$4^{-5}$} & $3.80 \mathrm{E}-2$ & $2.14 \mathrm{E}-2$ & $5.85 \mathrm{E}-3$ & $1.57 \mathrm{E}-3$ & $3.93 \mathrm{E}-4$ & $9.76 \mathrm{E}-5$ & $2.39 \mathrm{E}-5$ \\
\hline & 8 & 12 & 20 & 35 & 60 & 102 & 167 \\
\hline \multirow[t]{2}{*}{$4^{-6}$} & $2.47 \mathrm{E}-2$ & $3.96 \mathrm{E}-2$ & $2.21 \mathrm{E}-2$ & $6.05 \mathrm{E}-3$ & $1.62 \mathrm{E}-3$ & $4.03 \mathrm{E}-4$ & $9.90 \mathrm{E}-5$ \\
\hline & 6 & 8 & 12 & 20 & 33 & 57 & 96 \\
\hline \multirow[t]{2}{*}{$4^{-7}$} & $2.23 \mathrm{E}-2$ & $2.63 \mathrm{E}-2$ & $4.06 \mathrm{E}-2$ & $2.24 \mathrm{E}-2$ & $6.16 \mathrm{E}-3$ & $1.65 \mathrm{E}-3$ & $4.12 \mathrm{E}-4$ \\
\hline & 5 & 6 & 8 & 12 & 19 & 32 & 54 \\
\hline \multirow[t]{2}{*}{$4^{-8}$} & $2.25 \mathrm{E}-2$ & $1.08 \mathrm{E}-2$ & $2.71 \mathrm{E}-2$ & $4.11 \mathrm{E}-2$ & $2.26 \mathrm{E}-2$ & $6.21 \mathrm{E}-3$ & $1.67 \mathrm{E}-3$ \\
\hline & 4 & 5 & 6 & 8 & 11 & 18 & 30 \\
\hline \multirow[t]{2}{*}{$4^{-9}$} & $2.25 \mathrm{E}-2$ & $1.08 \mathrm{E}-2$ & $8.28 \mathrm{E}-3$ & $2.76 \mathrm{E}-2$ & $4.14 E-2$ & $2.27 \mathrm{E}-2$ & $6.24 \mathrm{E}-3$ \\
\hline & 4 & 4 & 5 & 6 & 7 & 11 & 17 \\
\hline \multirow[t]{2}{*}{$4^{-10}$} & $2.25 \mathrm{E}-2$ & $1.08 \mathrm{E}-2$ & $5.31 \mathrm{E}-3$ & $8.44 \mathrm{E}-3$ & $2.78 \mathrm{E}-2$ & $4.15 E-2$ & $2.28 \mathrm{E}-2$ \\
\hline & 3 & 4 & 4 & 5 & 6 & 7 & 10 \\
\hline \multirow[t]{2}{*}{$4^{-11}$} & $2.25 \mathrm{E}-2$ & $1.09 \mathrm{E}-2$ & $5.31 \mathrm{E}-3$ & $2.63 \mathrm{E}-3$ & $8.53 \mathrm{E}-3$ & $2.79 \mathrm{E}-2$ & $4.16 \mathrm{E}-2$ \\
\hline & 3 & 3 & 4 & 4 & 5 & 5 & 7 \\
\hline \multirow[t]{2}{*}{$4^{-12}$} & $2.25 \mathrm{E}-2$ & $1.09 \mathrm{E}-2$ & $5.32 \mathrm{E}-3$ & $2.63 \mathrm{E}-3$ & $2.17 \mathrm{E}-3$ & $8.57 \mathrm{E}-3$ & $2.80 \mathrm{E}-2$ \\
\hline & 3 & 3 & 3 & 4 & 4 & 4 & 5 \\
\hline
\end{tabular}


mesh, generates numerical solutions that converge parameter-uniformly in the maximum norm. This behaviour is in marked contrast to the numerical solutions generated by an analogous numerical method on a uniform mesh. We see also from the graphs, that the numerical solutions display no non-physical numerical oscillations, which are often an undesirable phenomenon that arises when classical numerical methods are used to solve problems with layers. We conclude therefore that the use of appropriately fitted piecewise-uniform meshes provides a remarkably simple solution to the problem of constructing satisfactory numerical solutions to problems involving boundary and interior layers.

\section{Acknowledgements}

This research was supported in part by the Enterprise Ireland grant SC-98-612, the Russian Foundation for Basic Research under grant No. 98-01-00362 and a research grant from the Australian Research Council.

\section{References}

[1] P.A. Farrell, J.J.H. Miller, E. O’Riordan, G.I. Shishkin, Singularly perturbed differential equations with discontinuous source terms, in: J.J.H. Miller, G.I. Shishkin and L.G. Vulkov (Eds.), Analytical and Numerical Methods for Convection-Dominated and Singularly Perturbed Problems, Nova, New York, to appear.

[2] H.K. Gummel, A self-consistent iterative scheme for one-dimensional steady state transistor calculation, IEEE Trans. Elec. Dev. 11 (1964) 455-465.

[3] J.J.H. Miller, E. O'Riordan, G.I. Shishkin, Fitted numerical methods for singular perturbation problems, World Scientific, Singapore, 1996.

[4] J.J.H. Miller, E. O'Riordan, G.I. Shishkin, Fitted mesh methods for the singularly perturbed reaction-diffusion problem, in: E. Minchev (Ed.), Proceedings of the 5th International Conference on Numerical Analysis, August, 1996, Academic Publications, Plovdiv, Bulgaria, 1996.

[5] G.I. Shishkin, Discrete Approximation of Singularly Perturbed Elliptic and Parabolic Equations, Russian Academy of Sciences, Ural section, Ekaterinburg, 1992 (in Russian).

[6] W.V. Van Roosbroeck, Theory of flow of electrons and holes in germanium and other semiconductors, Bell Syst. Tech. J. 29 (1950) 560-607. 